\title{
GOVERNANÇA PÚBLICA PARA GARANTIR O FINANCIAMENTO DOS DIREITOS SOCIAIS EM TEMPOS DE PANDEMIA
}

\author{
Mariana Passos Beraldo \\ Carla Abrantkoski Rister \\ Fernando Passos
}

Resumo: O COVID-19 veio para desafiar a humanidade, postulando soluções novas para problemas já conhecidos há tempos, tais como a excessiva desigualdade social. Contudo, a otimização da gestão publica se mostra como um desafio a ser superado. Trata-se de uma pesquisa de natureza aplicada, cujo problema foi abordado pela ótica qualitativa e com objetivo exploratório, viabilizado pelo estudo bibliográfico, cuja coleta de material focou na produção doutrinária nacional. Em relação aos procedimentos metodológicos, adotou-se a revisão integrativa enquanto ferramenta analítica. Os resultados demonstraram que o modelo de governança na gestão pública se mostra como imprescindível para manutenção dos direitos sociais essenciais.

Palavras-chave: Covid-19; Direitos sociais; Intervenção estatal no domínio econômico; Governança pública; Combate à corrupção

\section{PUBLIC GOVERNANCE TO ENSURE THE FINANCING OF SOCIAL RIGHTS IN PANDEMIC TIMES}

\begin{abstract}
COVID-19 came to challenge humanity, postulating new solutions to problems that have been known for a long time, such as excessive social inequality. However, the optimization of public management is a challenge to be overcome. It is an applied research, whose problem was approached from a qualitative point of view and with an exploratory objective, made possible by the bibliographic study, whose material collection focused on
\end{abstract}


national doctrinal production. Regarding the methodological procedures, the integrative review was adopted as an analytical tool. The results showed that the governance model in public management is shown to be essential for maintaining essential social rights.

Key words: Covid-19; Social rights; State intervention in the economic domain; Public governance; Fight against corruption

\section{INTRODUÇÃO}

O COVID-19 veio para desafiar a humanidade, postulando soluções novas para problemas muitas vezes já conhecidos há tempos, como excessiva desigualdade social, falta de saneamento básico, a adequada prestação do serviço de saúde pública e da seguridade social. Em razão do acentuado nível de pobreza e fome, aumenta a demanda por intervenção do Estado na economia para conter efeitos nefastos nas searas de saúde, social e econômica, além de conter externalidade negativas de sua ocorrência. De outro, mostra-se necessário a aplicação do desenvolvimento tecnológico no setor produtivo, para proposição de soluções e modelos de negócios que assegurem a produtividade e o bem-estar da população. Portanto, o trade of ampliação dos gastos e escassez de recursos surge com força.

Especialistas apontam que implicações negativas da crise são incomensuráveis no momento e tendem a ser catastróficas. Não se pode, todavia, assistir passivamente seus efeitos impactantes, devendo, ao revés, buscar soluções para contornar as externalidades negativas de sua ocorrência. O cenário mundial, que se repete no Brasil, repleto de incertezas, clama por intervenção Estatal, a partir da esfera federal, a quem compete fixar as diretrizes e medidas para enfrentamento da situação emergencial, apoiadas pelas iniciativas dos governos estaduais e municipais, no âmbito de suas atribuições (BRASIL, 1988).

Se, por um lado, medidas urgentes, nos mais diversos âmbitos, carecem de imediata aplicação para combater de forma eficaz o avanço e as consequências da doença, visando frear o cenário de intensa crise generalizada causada pela pandemia, por outro, depara-se com níveis de insegurança jurídica em proporções poucas vezes vivenciadas no passado. Tal fato ocorre em razão da nações, ao procurar mitigar os efeitos da crise, por meio da concessão de medidas que incluem a redução das taxas de juros e a introdução de estímulos econômicos, entre tantas 
outras em um cipoal de normas oriundas dos mais diversos entes normativos, causaram verdadeira inflação legislativa jamais vista em tempos modernos (PASSOS, 2020).

O reconhecimento e tutela dos direitos fundamentais é atividade que tem ocupado há séculos as mais diferentes nações. Como produto da história, tais direitos surgem e se acumulam aos já reconhecidos, exigindo dos diversos ordenamentos jurídicos e do poder público que se adaptem e promovam sua implementação. À medida que os direitos se acumulam, passam a demandar do Estado não só um dever de abstenção ou de não interferência, mas antes uma prestação positiva dependente de recursos para seu aperfeiçoamento e concretização, a qual, no entanto, é dificultada pela escassez de verbas disponíveis e pelos reflexos que os gastos estatais com esses direitos provocam na economia como um todo.

Neste contexto, fica evidente um dilema que cerca muitos Estados-Nação e diz respeito à ampliação ou redução do tamanho do Estado, à centralização e descentralização administrativa, à ampliação do estado de bem-estar social e o escopo da cidadania, ou à ampliação do estado neoliberal e redução dos direitos sociais. Esse dilema esteve presente na história e se revela no âmbito da produção científica e nas práticas eleitorais e governamentais.

Desse modo e em se encontrando o Estado em meio a uma verdadeira crise, em situações extremadas, tal qual a vivenciada no período da COVID-19, torna-se um desafio ainda maior a manutenção dos direitos sociais, expressamente resguardados pela nossa Carta Maior, uma vez que descartada qualquer possibilidade de negação ou redução desses direitos, eis que justamente através da sua consagração se busca minimizar a desigualdade social tão acentuada na sociedade brasileira, bem como promover a tão almejada justiça social.

O quadro retratado é agravado quando o recurso público não é bem empregado, seja por razões de gastos excessivos e desnecessários, a falta de adequado processo licitatório para contratações ou até por desvios de recursos e prática de corrupção envolvendo os gestores públicos. A Lei n. 13.979/2020, ao dispor sobre as medidas para enfrentamento da pandemia causada pelo coronavírus, dispensou, mesmo que temporariamente, a licitação para aquisição ou contratação de bens, serviços, inclusive de engenharia e insumos destinados ao enfrentamento da emergência de saúde pública (2020). Tal medida é plenamente justificada diante da necessidade de tomada de decisões urgentes, incompatíveis com a formalidade que emana o processo licitatório, entretanto, essa deliberalidade na contratação exige uma maior conscientização dos gestores públicos ao dispor sobre gastos públicos, evidenciando, mais do que nunca, a necessidade da governança pública e o combate à corrupção. 
Contextualizado a realidade atual, a justificativa deste artigo se encontra pautada na ascensão da crise financeira e social instalada no Estado brasileiro, que já se encontrava fragilizado antes da deflagração da pandemia, cujo cenário, diante do encolhimento da economia, tende a elevar o nível de pobreza da população brasileira, evidenciando o objetivo de se investigar acerca da possibilidade pelo Estado do financiamento dos direitos sociais, quer por meio de sua intervenção na economia e ou pela readequação da despesas públicas, sem imprescindível para sucesso da empreitada, a governança pública, com combate efetivo à corrupção e aos desvios de receitas públicas.

Para materializar os objetivos desta pesquisa, foi adotada a seguinte estratégia metodológica: pesquisa de natureza aplicada, pois visa gerar conhecimento voltado à solução ao quadro exposto; cujo problema foi abordado pela ótica qualitativa e com objetivo exploratório, viabilizado pelo estudo bibliográfico, cuja coleta de material focou na produção doutrinária nacional, publicada a partir da entrada em vigor da Constituição Federal, em 1988. Em relação aos procedimentos metodológicos, adotou-se a revisão integrativa enquanto ferramenta analítica.

O trabalho, dentro de um encadeamento lógico, está organizado em três capítulos, além deste, que se entrelaçam e se completam. A seção inicial parte de uma discussão teórica sobre a origem, a previsão constitucional e o financiamento dos direitos sociais, em especial, no contexto de crise econômica e social decorrente da pandemia da Covid-19. A segunda seção analisou o conceito de governança no setor público, enfatizando da necessidade de observância deste modelo na gestão das receitas publica.

Como resultados da pesquisa, se observou que ajustamento do orçamento público brasileiro foi imprescindível para que o Estado pudesse mitigar as consequências da pandemia do coronavírus e garantir a manutenção dos direitos sociais essenciais, mas do que nunca, tão necessários à população já fortemente marcada pela desigualdade social. Contudo, somente a o afrouxamento e readequação do orçamento não se mostrará eficaz para enfretamento da situação calamitosa instalada se a gestão dos recursos públicos não foi eficiente. Assim, ponderou-se que o governante em todas as instâncias federativas, cada um dentro de seu âmbito de atribuição, aja pautado na eficácia, eficiência e efetiva análise e gestão de riscos decorrentes das políticas públicas a serem implementadas e executadas para enfrentamento da pandemia, implementando, desta forma, o modelo de governança pública. Deve ainda o legislador, no exercício da função que lhe é própria, se dispor e efetivamente exercer o bom ofício de 
encontrar soluções novas e criativas para o problema de grande parte da população brasileira, sem acesso a condições dignas de vida e saúde já de longa data, em face de omissões e malversação de recursos.

\section{O FINANCIAMENTO DOS DIREITOS SOCIAIS DURANTE A PANDEMIA}

\subsection{A atividade financeira do Estado}

A atividade financeira do Estado é representada pelas ações que o Estado desempenha objetivando à obtenção dos recursos necessários ao seu sustento e a respectiva realização de gastos voltados a execução das necessidades públicas. Essa atividade depende de três elementos essenciais: a)elaboração do orçamento público, como peça delimitadora das receitas e despesas públicas, inerentes a um certo período; b) formas, condições e limites de obtenção de receitas para fazer frente às despesas fixadas; e c) formas, condições e limites de gasto do dinheiro público, bem como, os métodos de aplicação e dispêndio das respectivas despesas públicas.

De um modo geral, pontua-se que a atividade financeira do Estado pode ser analisada em dois períodos específicos em relação a sua atividade financeira: o período clássico e o período moderno. de acordo com Galvão (2015), este período estava ligado ao estado liberal dos séculos XVIII e XIX e caracterizou-se pelo princípio do não intervencionismo do estado no mundo econômico. neste período observou-se o mínimo possível de intervenção do estado na economia, este regime derrubou o estado absolutista monarca, sendo influenciado pelo: 1) individualismo filosófico (iluminismo) e político (revolução francesa) do século XVIII (proteção do indivíduo contra os abusos do estado, opunha-se ao absolutismo monárquico; e 2)liberalismo econômico que pregava o livre comércio e não admitia a intervenção estatal. sua principal característica era a liberdade econômica com mínima intervenção do estado. no período clássico a atividade financeira do estado visava somente à obtenção de recursos para custear as despesas públicas. o tributo tinha finalidade fiscal, pois não se intervinha nos domínios econômico e social.

Já o período Moderno começou a ser delineado a partir do final do século XIX com a ampliação das funções estatais decorrente de quatro fatores: I) As fortes oscilações econômicas dos países que passavam rapidamente de grande euforia econômica e financeira 
para depressão; II) Grandes crises econômico-financeiras provocadas pelo crescente desemprego dos períodos de depressão econômica, gerando tensões sociais; III) As grandes descobertas científicas e o efeito de suas aplicações; e IV) Os efeitos decorrentes da Revolução Industrial e o agravamento das condições materiais dos trabalhadores. De um modo geral, pontua-se que a Revolução Industrial modificou as condições de trabalho fazendo surgir o Direito do Trabalho, pois a partir desse marco histórico verifica-se a necessidade do Estado intervir nas relações trabalhistas, deixando, assim, de ser essencialmente liberal e tornando-se mais intervencionista, sobretudo através da instituição de tributos com finalidade extrafiscal (ou seja, ao mesmo tempo que um tributo visava a obtenção de recursos ele influenciava diretamente a economia) e através da personalização do imposto dando a cada produto um valor específico (GALVÃO, 2015).

Pondera-se que o caráter intervencionista do Estado se traduz na instituição de tributos com finalidade extrafiscal, além da nova visão de personalização do imposto, levando-se em conta a capacidade contributiva dos cidadãos. Segundo Galvão (2015), o Estado desenvolve atividades políticas, policiais, econômicas, sociais, administrativas, financeiras, educacionais, entre outras, cuja finalidade é regular a vida dos seus cidadãos em sociedade, de forma a se alcançar o bem comum. A atividade financeira do Estado está vinculada a satisfação de três necessidades básicas, apresentadas a seguir.

- Prestação de serviços públicos (art. 20 e 175 da Constituição Federal - CF): É a prestação de utilidade ou comodidade material fruível diretamente pelos cidadãos, prestado pelo Estado ou por quem faça suas vezes, sob regime, de direito público.

A Constituição Federal refere-se aos serviços públicos em vários dispositivos (art. 21, X a XIII, XV, XXII e XXIII).O art. 175 da CF prescreve que cabe ao poder público a prestação de serviços público, na forma da lei, diretamente ou sob o regime de concessão ou permissão, sempre por meio de licitação. Os tributos instituídos pelos Estados são compulsórios, ou seja, obrigatórios, pois não podemos escolher qual o tributo que iremos pagar (GALVÃO, 2015).

- Exercício regular do poder de polícia (art. 78 do CTN): O art. 78 do CTN dispõe sobre o poder de polícia, como sendo a "atividade da administração pública que, limitando ou disciplinando direito, interesse ou liberdade, regula a prática de ato ou abstenção de fato, em razão do interesse público concernente à 
segurança, à higiene, à ordem, aos costumes, à disciplina da produção e do mercado, ao exercício de atividades econômicas dependentes de concessão ou autorização de Poder Público, à tranquilidade pública ou ao respeito à propriedade e aos direitos individuais ou coletivos" (GALVÃO, 2015).

O paragrafo único do artigo 78 prescreve que "considera-se regular o exercício do poder de polícia quando desempenhado pelo órgão competente nos limites da lei aplicável, com observância do processo legal e, tratando-se de atividade que a lei tenha como discricionária, sem abuso ou desvio de poder".

De acordo com Galvão (2015), o Poder de Polícia nada mais do que um poder regulamentador de que o Estado está investido, discricionário, mas limitado por lei. Objetiva intervir na propriedade e na liberdade individual, impondo aos indivíduos comportamento comissivo ou omissivo, em benefício do interesse da coletividade. $\mathrm{Na} \mathrm{CF}$, em vários dispositivos, refere-se à manifestação do poder de polícia (arts. 145, II, 170, 174, 182, 192 e 193 CF/88). O emprego do poder de polícia no campo da tributação tem sido frequente em nosso ordenamento jurídico, doutrinariamente traduz-se pelos tributos de cunho extrafiscal, decretado como instrumento regulatório de atividades.

- Intervenção no domínio econômico: A CF consagra como princípio fundamental a livre iniciativa (art. $1^{\circ}$, IV e art. 170, I a IX), pois é assegurado a todos o livre exercício de qualquer atividade econômica, independentemente de autorização de órgãos públicos, salvos os casos previstos em lei. De acordo com a nossa constituição em seus arts 170 e 173 na nossa economia prevalece a livre iniciativa, mas o estado também pode exercer atividade econômica como uma das formas de captação de recursos para atingir seus objetivos em planos organizacionais (GALVÃO, 2015).

Segundo o autor, o Estado intervém na atividade econômica por meio de seu poder normativo, elaborando leis de combate ao abuso do poder econômico, leis de proteção ao consumidor e leis tributárias de natureza extrafiscal. A EC42/2003acresceu o art.146-A, inserindo na competência da lei complementar a faculdade de estabelecer critérios especiais de tributação, para prevenir desequilíbrios da concorrência. A tributação como relação jurídica e não apenas uma relação de poder. O Princípio da Legalidade Tributária dispõe que a tributação 
também é uma relação jurídica, e não apenas uma relação de poder soberano do estado, pois temos normas jurídicas limitando esse poder.

Denota-se que a intervenção do estado ocorre por implementação do gasto público, o qual é normatizado em um orçamento, submetido ao controle da administração e ao controle social. Neste contexto, Calado (2012) apresenta as funções do orçamento público, divididas em 3: a)Alocativa - Utilização dos recursos totais da economia, incluindo a oferta de bens públicos, podendo criar incentivos para desenvolver mais certos setores em relação a outros; b) Distributiva - Combate os desequilíbrios regionais e sociais, promovendo o desenvolvimento das regiões e classes menos favorecidas; e c) estabilizadora - Escolhas orçamentárias na busca do pleno emprego dos recursos econômicos; da estabilidade de preços; do equilíbrio da balança de pagamentos e das taxas de câmbio, tudo isso visando o crescimento econômico em bases sustentáveis.

Como pontuado, todo gasto público se submete ao controle. Controlar significa verificar se a realização de uma determinada atividade não se desvia dos objetivos ou das normas e princípios que a regem (SOUZA et al., 2012). Na Administração Pública, o ato de controlar possui significado similar, na medida em que pressupõe examinar se a atividade governamental atendeu à finalidade pública, à legislação e aos princípios básicos aplicáveis ao setor público (SOUZA et al., 2012). Na ciência jurídica, controle recebe uma conotação normativa. Segundo denominação dada por José dos Santos Carvalho Filho, tem-se por controle da Administração Pública "o conjunto de mecanismos jurídicos e administrativos por meio dos quais se exerce o poder de fiscalização e revisão da atividade administrativa em qualquer das esferas de Poder" (CARVALHO FILHO, 2009, p. 893). Consoante Hely Lopes Meirelles salienta que, “controle, em tema de Administração Pública, é a faculdade de vigilância, orientação e correção que um Poder, órgão ou autoridade exerce sobre a conduta funcional de outro" (MEIRELLES, 2010, p. 697). De acordo com Maria Sylvia Di Pietro, a finalidade do controle é "a de assegurar que a administração atue em consonância com os princípios que lhe são impostos pelo ordenamento jurídico, como os da legalidade, moralidade, finalidade pública, publicidade, motivação, impessoalidade; em determinadas circunstâncias, abrange também o controle chamado de mérito e que diz respeito aos aspectos discricionários da atuação administrativa" (DI PIETRO, 2010, p. 728).

A forma de controle exercida pela própria Administração Pública e por organizações privadas é chamada de controle institucional. Na administração pública, é exercida por órgãos 
que têm a competência legal para fiscalizar a aplicação dos recursos públicos (SOUZA et al., 2012). Os artigos 70, 71 e 74 da Constituição Federal brasileira estabelecem que o controle institucional cabe essencialmente ao Congresso Nacional, responsável pelo controle externo, realizado com o auxílio do Tribunal de Contas da União, e a cada Poder, por meio de um sistema integrado de controle interno (SOUZA et al., 2012).

Outros órgãos públicos também atuam na prevenção, controle, investigação e repressão da corrupção: o Ministério Público Federal, os Ministérios Públicos Estaduais, o Tribunal de Contas da União, os Tribunais de Contas dos Estados e dos Municípios, as Controladorias dos Estados, a Polícia Federal, as Polícias Estaduais, o Poder Legislativo e o Poder Judiciário, apenas para citar os órgãos mais evidentes (SOUZA et al., 2012).

Entretanto, tendo em vista a complexidade das estruturas político-sociais de um país e do próprio fenômeno da corrupção, o controle da Administração Pública não se deve restringir ao controle institucional. É fundamental para toda a coletividade que ocorra a participação dos cidadãos e da sociedade organizada no controle do gasto público, monitorando permanentemente as ações governamentais e exigindo o uso adequado dos recursos arrecadados. A isto se denomina "controle social" (SOUZA et al., 2012).

\subsection{A tutela dos direitos fundamentais na teia da atividade financeira do Estado}

O reconhecimento e tutela dos direitos fundamentais é atividade que tem ocupado há séculos as mais diferentes nações. Como produto da história, tais direitos surgem e se acumulam aos já reconhecidos, exigindo dos diversos ordenamentos jurídicos e do poder público que se adaptem e promovam sua implementação, a qual, no entanto, é dificultada pela escassez de verbas disponíveis e pelos reflexos que os gastos estatais com esses direitos provocam na economia como um todo.

O Pacto Internacional dos Direito Econômicos, Sociais e Culturais, aprovado pela Assembleia Geral da ONU em 16 de dezembro de 1966 e tendo entrado em vigor em 3 de janeiro de 1976, foi o primeiro instrumento jurídico do âmbito das Nações Unidas a detalhar os direitos de segunda geração. Os Estados, ao firmarem o Pacto, reconheceram os direitos econômicos, sociais e culturais referidos no tratado e se comprometeram a assegurá-los progressivamente, diante da existência de recursos econômicos próprios ou com cooperação internacional, a seus cidadãos (MAZZUOLI, 2015). 
O Pacto foi aprovado no Brasil pelo Decreto Legislativo ${ }^{\circ}$. 226, de 12 de dezembro de 1991 e incorporado por meio do Decreto $n^{\circ} .591$, de 6 de julho de 1992. Dentre os direitos consagrados no tratado, destacam-se para o presente trabalho: (i) o direito de toda pessoa ter a possibilidade de ganhar a vida mediante um trabalho livremente escolhido ou aceito (art. $6^{\circ}$, $\S 1^{\circ}$ ); (ii) o direito de toda pessoa de gozar de condições de trabalho justas e favoráveis, assegurando especialmente um remuneração que proporcione, no mínimo, a todos os trabalhadores uma existência decente para os trabalhadores e suas famílias (art. $7^{\circ}$ ); (iii) o direito à previdência social, inclusive ao seguro social (art. $9^{\circ}$ ); (iv) o direito de toda pessoa a um nível de vida adequada para si próprio e para a sua família, inclusive à alimentação, vestimenta e moradia adequadas, assim como a uma melhoria contínua de suas condições de vida $\left(\operatorname{art.~} 11^{\circ}, 1^{\circ}\right)$; (v) o direito de toda pessoa à educação, que deverá visar ao pleno desenvolvimento da personalidade humana e do sentido de sua dignidade e a fortalecer o respeito pelos direitos humanos e liberdades fundamentais (art. 13º $\S^{\circ}{ }^{\circ}$ ) (BRASIL, 1992).

Nota-se que a Constituição Federal de 1988, além de promover a redemocratização do país, estabeleceu extenso rol de direitos fundamentais e coletivos, muitos deles que demandam prestações positivas por parte do Estado; porém, a perfeita observância de seus preceitos tem sido um desafio à sociedade brasileira desde sua a promulgação, até mesmo em face da imprevidência na elaboração e execução de políticas públicas pelo Estado brasileiro.

Dentro desse escopo, o constituinte salvaguardou recursos permanentes e estáveis para a cobertura das despesas decorrentes dos direitos sociais. Além dessa vinculação, foi admitida, em nível constitucional, a destinação de receitas a fundos de desenvolvimento regional (REZEK, 2011). Assim, o legislador constituinte, além de atentar-se a regulação da ordem econômica, exprimiu preocupação com relação à ordem social, que tem como fundamento o trabalho e como objetivo o bem-estar e justiça sociais (artigo 193 da CF), uma vez que o desenvolvimento social é fim último e a vertente mais robusta do desenvolvimento, tomado em seu sentido lato (RISTER, 2007, p. 387).

Pontua-se, no entanto, que em se encontrando o Estado em meio a uma verdadeira crise, tal qual a vivenciada no período da COVID-19, torna-se um desafio maior a manutenção dos direitos sociais. O enfrentamento dessa problemática, porém, não pode conduzir à negação ou redução desses direitos.

Dentre as políticas sociais implementadas neste período destacam-se: (i) diferimento, pelos empregadores, do recolhimento do Fundo de Garantia do Tempo de Serviço - FGTS; (ii) 
benefício emergencial de preservação do emprego e da renda; (iii) saque do saldo da conta do FGTS; (iv) descontos tarifários no fornecimento de energia elétrica dos consumidores finais integrantes da Subclasse Residencial Baixa Renda; e (v) facilitação do acesso ao crédito.

Do mesmo modo, com a crise econômica ocasionada pela Covid-19, o Governo Brasileiro se socorre de medidas fiscais para preservação da economia que se encontra fortemente abalada, devido à paralisação horizontal do país (BRASIL, 2020). Os incentivos fiscais já lançados, tais como a desoneração, redução de alíquotas a zero, incremento e diminuição de custos de produção de certos materiais necessários à utilização do combate à Covid-19 tornam-se estratégia política-tributária, a fim de solavancar a devastada situação econômica do Brasil. A postergação do vencimento do pagamento dos tributos federais, outra estratégia econômica adotada, também contribui, já que possibilita a manutenção do fluxo de caixa das empresas.

Outras tantas medidas provisórias determinam a abertura de crédito extraordinário, tais como a MP n 969, de maio de 2020, que abre crédito extraordinário, em favor do Ministério da Saúde, no valor de R \$10.000.000.000,00 (dez bilhões), para possibilitar o enfrentamento da emergência de saúde pública de importância internacional decorrente do coronavírus (BRASIL, 2020).

Percebe-se que as medidas adotadas, visando enfrentamento da crise e como forma de assegurar a manutenção dos direitos sociais, dependem de financiamento do Estado, muitas vezes via ampliação do gasto público, verificando-se assim, a necessária interação entre a ordem econômica, a ordem social e o ordenamento normativo do Estado. A articulação entre direito e economia, que compreende uma visão econômica da sociedade, acrescida de ideais morais sobre o bem ou justiça, há tempos tem sido reconhecida por profissionais da área, quer economistas, quer juristas. Vale ressaltar que o próprio Adam Smith, no início de sua carreira acadêmica, dedicou-se à filosofia moral e ao direito (CASTRO, 2015).

Desse modo, a questão da distribuição das riquezas associada à ideia de alargamento da cidadania e promoção de justiça social tem ocupado nos últimos anos as pesquisas dos economistas e cientistas políticos, pautando a agenda dos políticos e sendo objeto de disciplina pela ciência jurídica, na medida em que políticas de redistribuição de renda e promoção da equidade entre os indivíduos, por serem na maior parte das vezes implantadas pelo Estado, dependem de leis que as veiculem, inserindo-se, por conseguinte, na dinâmica própria do Direito, propiciando os contornos necessários para disseminação das políticas de Estado. 
Neste contexto, verifica-se o papel que o Estado deve desempenhar na sociedade e como agente econômico a fim de garantir os direitos sociais que podem minimizar o cenário de desigualdade social tão inflamado. Salienta-se que a intervenção governamental via gastos públicos, em situação de crise econômica, já foi defendida por John Maynard Keynes, no século XX, como sendo fundamental para tirar a economia da recessão. Em situações de guerra, situações estas em que se enquadra a calamidade pública, permite-se um alargamento da despesa pública, pois se trata de um período com grandes distúrbios sociais, identificando-se a necessidade de realocação de orçamento e adoção de medidas emergenciais para contenção do dispêndio econômico, social e político decorrente da situação extremada.

Necessário frisar que políticas keynesianas devem ser passageiras, cujo intuito principal é propiciar condições para a recuperação da economia, devendo sanadas e substituídas por outras políticas para evitar ciclos nefastos de desenvolvimentos (PEACOCK; WISEMAN, 1967)

As políticas baseadas em Keynes proporcionam aos governos flexibilização institucional via gerenciamento das finanças públicas (CASTRO, 2015). Neste momento de enfrentamento da emergência de saúde pública decorrente do coronavírus, a intervenção estatal proporcionou flexibilização orçamentária e foi amplamente engendrada pelas instâncias governamentais e legislativas e pontualmente incorporadas na agenda governamental para enfrentamento dos efeitos nefastos da pandemia.

A flexibilização orçamentaria foi reconhecida pelo judiciário quando o Ministro Alexandre de Moraes, do Supremo Tribunal Federal (STF), deferiu, em 29 de março, medida cautelar na Ação Direta de Inconstitucionalidade (ADI) 6357, posteriormente referendada, por maioria, pelo STF em 15 de abril de 2020, concedendo interpretação conforme à Constituição Federal aos artigos 14, 16, 17 e 24 da Lei de Responsabilidade Fiscal e 114, caput, in fine e $\S$ 14, da Lei de Diretrizes Orçamentárias/2020, “para, durante a emergência em Saúde Pública de importância nacional e o estado de calamidade pública decorrente da Covid-19, afastar a exigência de demonstração de adequação e compensação orçamentárias" prevista nestes dispositivos. Esses dispositivos legais exigem, para o aumento de gastos tributários indiretos e despesas obrigatórias de caráter continuado, "as estimativas de impacto orçamentáriofinanceiro e a compatibilidade com a LDO, além da demonstração da origem dos recursos e a compensação de seus efeitos financeiros nos exercícios seguintes”. A importante decisão destacou "que a medida cautelar se aplica a todos os entes federativos que, nos termos 
constitucionais e legais, tenham decretado estado de calamidade pública decorrente da pandemia da Covid-19” (BRASIL, 2020). Após referendar a medida cautelar concedida, o Plenário da Corte Maior, ao analisar pedido da Advocacia-Geral da União (AGU), declarou a extinção da ação, por perda de objeto, em razão da aprovação da Emenda Constitucional (EC) 106/2020 ("Orçamento de Guerra").

Com relação a preservação dos direitos sociais em tempos de crise, há que se fazer uma ponderação no sentido de separar aquilo que a Constituição já havia elencado como direito social e não foi garantido à população e medidas emergenciais que não poderão perenizar, sob pena de inviabilizar todo o sistema de custeio dos direitos sociais. E essa distinção não há de ser acrítica; o legislador, desde a posição privilegiada que ocupa para representação dos interesses da população, deverá posicionar as medidas emergenciais dentro de uma hierarquia bem estabelecida (RUGGERI, 2015), de tal forma que a prioridade na alocação de recursos seja facilmente identificada evitando assim, o esbanjamento de recursos públicos, que normalmente já são escassos.

Portanto, as ações tomadas pelo governo brasileiro para mitigação dos impactos da pandemia, com a finalidade preponderante de assegurar a manutenção dos direitos sociais clamados pela Constituição Federal, dependem de recursos público. Assim, imprescindível e justificável intervenção do Estado no domínio econômico para preservar e garantir os direitos sociais que se refletem na manutenção da cidadania e da justiça social. Contudo, a dificuldade está em se garantir o emprego eficaz das receitas públicas, especialmente em razão da autorizada contratação deliberada, pelos agentes públicos de todo aparato necessário para enfrentamento da emergência de saúde pública instalada em todo território nacional. Neste contexto, mais do que nunca, se clama pela boa governança no setor público.

\section{GOVERNANÇA PÚBLICA E COMBATE À CORRUPÇÃO VISANDO MELHOR GESTÃO DO ORÇAMENTO PÚBLICO EM TEMPO DE PANDEMIA}

A flexibilização e ajustamento do orçamento público brasileiro foi imprescindível para que o Estado pudesse mitigar as consequências da pandemia do coronavírus e manter os direitos sociais, mas do que nunca, tão necessários a uma população já marcada pela desigualdade social. Contudo, somente a readequação do orçamento não se mostrará eficaz para enfretamento da situação calamitosa instalada se a gestão dos recursos públicos não se mostrar eficaz. 
O conceito de governança decorre do setor privado, imputado como um modo de gestão das sociedades empresárias, conhecido como governança corporativa ou compliance empresarial e decorre do adequado controle dos atos e visa evitar o surgimento de possíveis conflitos de interesses entre os envolvidos (FORTINI; SHERMAM, 2020).

No contexto atual de mercado global, organizações internacionais, como a Organização para a Cooperação e o Desenvolvimento Econômico - OCDE, trabalham os princípios e diretrizes relacionais à governança corporativa. Mas não é só, essas organizações também estendem a necessidade de observância das diretrizes no setor público. O OECD Guidelines on Corporate Governance of State-Owned Enterprises inspirou as normas sobre governança presentes na Lei das Estatais brasileiras (Lei n ${ }^{\circ} 13.303 / 2016$ ).

$\mathrm{Na}$ esfera pública a governança consiste em um programa normativo que preze pela eficácia, eficiência e efetiva análise e gestão de riscos decorrentes de políticas públicas implementadas e executadas pelos mais diversos setores da Administração Pública (MESQUITA, 2019).

Há décadas o aparato legislativo nacional já direciona no sentido de criar mecanismos para identificação, inibição e punição dos atos lesivos praticados contra o patrimônio público, a saber: Lei de Improbidade Administrativa (Lei $n^{\circ}$ 8.429/92); Lei Geral de Licitações e Contratos (Lei n 8.666/93); Lei de Acesso à Informação (Lei no 12.527/11); Lei Anticorrupção (Lei $n^{\circ} 12.846 / 13$ ); Lei Orgânica do TCU (Lei no 8.443/92); Lei de Licitações (Lei $n^{\circ}$ 8.666/93) e por fim, a inclusão das letras "B" e "D" no art. 337 do Código Penal que tipifica a corrupção internacional (SANTOS, 2018). Um processo de maior conscientização quanto aos danos decorrente de práticas e condutas ilícitas nos negócios para o desempenho econômico e social das nações desencadeou no incremento das regras de controle institucional com o propósito de, principalmente, reduzir essas práticas nefastas (SANTOS, 2018).

Atualmente o Brasil é signatário de três convenções internacionais de prevenção e combate à corrupção, incluindo a Convenção das Nações Unidas contra a Corrupção, que tratase do principal instrumento internacional de combate à corrupção, quer pelo número de signatários, quer pela abrangência de matérias cuidadas, assinada em 2003, e somente em 2006 entrou em vigor no Brasil, pelo Decreto no 5.687/2006. A devida gestão dos assuntos e dos bens públicos esta entre as finalidades da Convenção da Nações Unidas.

Assim, para que de fato se tenha um Estado Democrático de Direito é mister assegurar que todos seus recursos sejam destinados para a conquista de bens e vantagens previstos na 
norma constitucional. É neste diapasão que está contido a governança na administração pública já que o Estado é instrumento da própria sociedade que visa a garantia e à promoção de direitos fundamentais à todos (PAULSEN, 2020) e sobretudo é deste Estado a obrigação de impedir que esta estrutura sirva para outros fins que não os constitucionais que visam mitigar as desigualdades sociais como as de raça, gênero e classe. Assim, esse modelo de gestão foi incorporado pelo setor público, visando, em especial, a prevenção e o combate à corrupção

\section{CONSIDERAÇÕES FINAIS}

Percebeu-se que a promoção de políticas públicas voltadas à redução de desigualdade, demanda de um lado, intervenção econômica capaz de garantir a sobrevivência de diverso espectros empresariais, de outro a intervenção para garantir condições mínimas de bem-estar social. De nada adianta garantir direitos sociais, se as empresas não se manterem saudáveis, gerando empregos e receita para o Estado.

Fazendo um paralelismo entre as medidas emergenciais deduzidas no momento atual de pandemia e a preservação dos direitos sociais, remete-se à questão de que em sendo muitas as demandas e poucos os recursos, faz-se imperioso o estabelecimento de uma mais criteriosa hierarquia entre os direitos, de modo a se eleger prioridades.

Procedendo-se desse modo, evita-se que os direitos fundamentais como um todo acabem se tornando meras declarações de boas-intenções, impedindo, assim que certas necessidades essenciais restem desatendidas. A partir de um núcleo essencial, e dentro de uma hierarquia bem definida, a implementação dos direitos fundamentais, no momento focada naqueles direitos econômicos e sociais básicos como alimentação, trabalho e moradia, poderá progredir, na medida em que as experiências bem-sucedidas se consolidem e mecanismos mais desenvolvidos de financiamento sejam criados. Tal comportamento, longe de ser uma opção política, é mais uma imposição constitucional, já que o combate à pobreza e a redução das desigualdades é um dos objetivos da República Federativa do Brasil.

Pontua-se por fim, que o equilíbrio entre vinculação de receitas e flexibilidade orçamentária é questão complexa cujo deslinde escapa aos objetivos deste artigo. O que se propôs é que, independentemente da solução encontrada, já que os recursos nunca serão abundantes o suficiente, especialmente num momento extremamente delicado e particular da história recente, é que o governante em todas as instâncias federativas, cada um dentro de seu 
âmbito de atribuição, em observância ao modelo de governança, aja pautado na eficácia, eficiência e efetiva análise e gestão de riscos decorrentes das políticas públicas a serem implementadas e executadas para enfrentamento da pandemia. Assim como deve o legislador, no exercício da função que lhe é própria, se dispor e efetivamente exercer o bom ofício de encontrar soluções novas e criativas para o problema de grande parte da população brasileira, sem acesso a condições dignas de vida e saúde já de longa data, em face de omissões e malversação de recursos.

Desta forma, o que não se pode é admitir que os direitos fundamentais continuem a ser negligenciados, o que seria uma catástrofe ainda maior que a pandemia ou ainda que demandas menos essenciais sejam atendidas em detrimento de outras de maior essencialidade.

\section{REFERÊNCIAS}

BRASIL, DECRETO No 591, DE 6 DE JULHO DE 1992. Atos Internacionais. Pacto Internacional sobre Direitos Econômicos, Sociais e Culturais. Promulgação. Disponível em: http://www.planalto.gov.br/ccivil_03/decreto/1990-1994/d0591.htm. Acesso em 15 de abr. de 2020.

BRASIL. Constituição da República Federativa do Brasil de 1988. Diário Oficial da União, Brasília, DF. Disponível em:

http://www.planalto.gov.br/ccivil_03/constituicao/constituicao.htm. Acesso em 15 de abr. de 2020.

BRASIL. Lei n ${ }^{\circ}$ 13.979, de 6 de fevereiro de 2020. Diário Oficial da União, Brasília, DF, Disponível em: http://www.planalto.gov.br/ccivil_03/_ato2019-2022/2020/lei/L13979 . Acesso em 15 de abril de 2020.

BRASIL. Medida Provisória n ${ }^{\circ}$ 969, de 20 de maio de 2020. Diário Oficial da União, Brasília, DF, Disponível em: https://www.in.gov.br/en/web/dou/-/medida-provisoria-n-969de-20-de-maio-de-2020-257675157. Acesso em 10 julho de 2020

BRASIL. Supremo Tribunal Federal. ADI 6357.Relator Ministro Alexandre de Moraes. Disponível em:http://www.stf.jus.br/arquivo/cms/noticiaNoticiaStf/anexo/ADI6357MC.pdf. Acesso em :17 de abr. de 2020.

CALADO, E. Coletânea de conceitos básicos de finanças públicas para utilização na aplicação de recursos orçamentários nos projetos de extensão. Brasília/DF: Ministério da Educação, 2012.

CASTRO, Marcus. Finanças, Política Econômica e Fruição de Direitos na Economia de Mercado: Alguns Desafios Contemporâneos. SSRN, 2015. Disponível em: https://ssrn.com/abstract=2646306. Acesso em 15 de maio de 2020. 
GALVÃO, A. A atividade financeira do estado. [S.1], 2015.

MEIRELLES, H. L. Direito Municipal Brasileiro. 14ª ed. São Paulo: Malheiros, 2006.

MESQUITA, Camila Bindilatti Carli de. O que é compliance público? Partindo para uma Teoria Jurídica da Regulação a partir da Portaria no 1.089 (25 de abril de 2018) da Controladoria-Geral da União (CGU). Revista de Direito Setorial e Regulatório, Brasília, maio 2019. Disponível em: https://periodicos.unb.br/index.php/rdsr/article/view/20587. Acesso em 31 de julho de 2020.

PASSOS, Fernando. Vírus atinge a inovação industrial 4.0 e a nossa própria essência. Uniara Notícias. Disponível em: https://www.uniara.com.br/noticias/47696/artigo-virus-atinge-ainovacao-industrial-40-e-a-nossa-propria-essencia/. Acesso em 16 de abril de 2020

PEACOCK, A. T.; WISEMAN, J.. The growth of public expenditure in the United Kingdon. Londres: George Allen \& Urwin, 1967.

REZEK, Francisco. A ética da ordem econômica na Constituição do Brasil. In: MARTINS, Ives Gandra da Silva; MEYER-PFLUG, Samantha; (coords). A intervenção do Estado no domínio Econômico: condições e limites - homenagem ao Prof. Ney Prado. São Paulo: LTr, 2011. ISBN 978-85-361-1784-3

RISTER, Carla Abrantkoski. Direito ao desenvolvimento - antecedentes, significados e consequências. Renovar, Rio de Janeiro, 2007.

RUGGERI, Antonio. O Futuro dos direitos fundamentais: viagem aventurosa no descunhecido ou retorno ao passado? In: ROMBOLI, Roberto; ARAÚJO, Marcelo Labanca Corrêa (orgs.); traduzido do italiano para o português por Alessandro Landini... [et al.].

Justiça Constitucional e Tutela Jurisdicional dos Direitos Fundamentais. Belo Horizonte: Arraes, 2015. ISBN 978-85-238-079-6

SANTOS, Diogo de Almeida Viana dos. Compliance e legislação anti-corrupção: uma perspectiva comparada. Revista Brasileira de Filosofia do Direito. Salvador. Jan/jun 2018. e-ISSN: 2526-012X. Disponível em: https://core.ac.uk/download/pdf/210567734.pdf. Acesso em 20 de agosto de 2020. 